\title{
Fixed point theorem for new type of auxiliary functions
}

\author{
Vishal Gupta \\ Department of Mathematics, \\ Maharishi Markandeshwar, Deemed to be \\ University, Mullana, Haryana, India \\ email: vishal.gmn@gmail.com, \\ vgupta@mmumullana.org
}

\author{
A. H. Ansari \\ Department of Mathematics, \\ Karaj Branch, Islamic Azad University, \\ Karaj, Iran \\ email: analsisamirmath2@gmail.com
}

\author{
Naveen Mani \\ Department of Mathematics, \\ Sandip University, Nashik, \\ Maharashtra, India \\ email: naveenmani81@gmail.com
}

\begin{abstract}
In this paper, we present some fixed point results satisfying generalized contractive condition with new auxiliary function in complete metric spaces. More precisely, the structure of the paper is the following. In the first section, we present some useful notions and results. The main aim of second section is to establish some new fixed point results in complete metric spaces. Finally, in the third section, we show the validity and superiority of our main results by suitable example. Also, as an application of our main result, some interesting corollaries have been included, which make our concepts and results effective. Our main result generalizes some well known existing results in the literature.
\end{abstract}

\section{Introduction and preliminaries}

The Banach contraction principle [10] is one of the revolutionary results of the fixed point theory, and it plays an imperative role to solve existence problems

2010 Mathematics Subject Classification: 47H10, 54H25

Key words and phrases: fixed point, auxiliary function, metric spaces 
in many branches of nonlinear analysis. Inspired from the impact of this natural idea to functional analysis, a number of researchers have been extended and generalized this principle for different kinds of contractions in various spaces.

Let us denote:

$\Psi_{1}=\left\{\psi_{1}:[0, \infty) \rightarrow[0, \infty)\right.$ is a continuous and non-decreasing function such that $\psi_{1}(\mathrm{t})=0$ if and only if $\left.\mathrm{t}=0.\right\}$ (Altering distance function)

$\Psi_{2}=\left\{\psi_{2}:[0, \infty) \rightarrow[0, \infty)\right.$ is a continuous function such that $\psi_{2}(0) \geq 0$ and $\left.\psi_{2}(\mathrm{t})>0, \mathrm{t}>0.\right\}$ (Ultra-altering distance function)

$\Psi_{3}=\{\varphi:[0, \infty) \rightarrow[0, \infty)$ is a Lebesgue-integrable function, summable on each compact subset of $\mathrm{R}^{+}$, non-negative, and such that for each $\epsilon>0$, $\int_{0}^{\epsilon} \varphi(t) d t>0$.

In 2002, Branciari [3] introduced one of the genuine contraction, known as integral type contraction, as an analogue of Banach contraction principle [10].

Theorem 1 [3] Let $(\mathrm{E}, \mathrm{d})$ be a complete metric space, $\mathrm{k} \in(0,1)$, and $\mathrm{A}: \mathrm{E} \rightarrow$ $\mathrm{E}$ is such that for each $\mathrm{x}, \mathrm{y} \in \mathrm{E}$

$$
\int_{0}^{d(A x, A y)} \varphi(t) d t \leq k \int_{0}^{d(x, y)} \varphi(t) d t
$$

where $\varphi \in \Psi_{3}$. Then $\mathrm{A}$ has a unique fixed point of $z \in \mathrm{E}$.

Rhoades [5], in 2003, gave an extension of the result of Branciari [3] and proved following theorems.

Theorem 2 [5] Let $(\mathrm{E}, \mathrm{d})$ be a complete metric space and $\mathrm{A}: \mathrm{E} \rightarrow \mathrm{E}$ be a mapping such that,

$$
\int_{0}^{d(A x, A y)} \varphi(t) d t \leq \beta \int_{0}^{M(x, y)} \varphi(t) d t,
$$

where

$$
M(x, y)=\max \left\{d(x, y), d(x, A x), d(y, A y), \frac{d(x, A y)+d(y, A x)}{2}\right\}
$$

for all $x, y \in \mathrm{E}, \beta \in[0,1)$ and $\varphi \in \Psi_{3}$. Then $\mathrm{A}$ has a unique fixed point $z \in \mathrm{E}$.

Theorem 3 [5] Let us consider a complete metric space $(\mathrm{E}, \mathrm{d})$ and $\mathrm{A}: \mathrm{E} \rightarrow \mathrm{E}$ is a mapping such that,

$$
\int_{0}^{\mathrm{d}(A x, A y)} \varphi(\mathrm{t}) \mathrm{dt} \leq \beta \int_{0}^{\mathrm{N}(x, y)} \varphi(\mathrm{t}) \mathrm{dt},
$$


where

$$
N(x, y)=\max \{d(x, y), d(x, A x), d(y, A y), d(x, A y), d(y, A x)\}
$$

for each $x, y \in E, \beta \in[0,1)$ and $\varphi \in \Psi_{3}$. Then there exist a unique fixed point $z \in \mathrm{E}$ such that $\mathrm{Az}=z$.

In 2010, Babu and Alemayehu [7] proved following theorem in complete metric spaces by using generalized $\phi-$ weak contraction.

Theorem 4 [7] Let us consider a complete metric space $(\mathrm{E}, \mathrm{d})$ and $\mathrm{A}: \mathrm{E} \rightarrow \mathrm{E}$ is such that for all $\mathrm{x}, \mathrm{y} \in \mathrm{E}$ it satisfies

$$
d(A x, A y) \leq M(x, y)-\phi(M(x, y))
$$

where

$$
M(x, y)=\max \left\{d(x, y), d(x, A x), d(y, A y), \frac{d(x, A y)+d(y, A x)}{2}\right\},
$$

and $\phi:[0,+\infty) \rightarrow[0,+\infty)$ such that $\phi(\mathrm{t})=0$ if and only if $\mathrm{t}=0$. Then there is a unique fixed point of $\mathrm{A}$ in $\mathrm{E}$.

In 2011, Samet and Yazidi [6] gave an extension of the result of Dass and Gupta [4] in the sense of Branciari integral type contraction, as follows

Theorem 5 [6] Let (E, d) be a complete metric space and A be a self-map of $\mathrm{E}$ such that for each $\mathrm{x}, \mathrm{y} \in \mathrm{E}$,

$$
\int_{0}^{d(A x, A y)} \varphi(t) d t \leq \alpha \int_{0}^{M(x, y)} \varphi(t) d t+\beta \int_{0}^{d(x, y)} \varphi(t) d t
$$

and

$$
M(x, y)=\frac{d(y, A y)[1+d(x, A x)]}{[1+d(x, y)]}
$$

where $\alpha, \beta>0$ are constants such that $\alpha+\beta<1$ and $\varphi \in \Psi_{3}$.

Then $A$ admits a unique fixed point $z \in E$ such that for each $z \in E, A^{n} x \rightarrow z$ as $\mathrm{n} \rightarrow \infty$.

In 2011, Gupta and Mani [14] proved a common fixed point theorem for two weakly compatible mappings using control functions $\psi_{1}$ and $\psi_{2}$ satisfying a contractive condition of integral type. 
Theorem 6 Let A and B be self compatible maps of a complete metric space $(\mathrm{E}, \mathrm{d})$ satisfying the following conditions:

(i). $A(E) \subset B(E)$

(ii). $\psi_{1}\left(\int_{0}^{d(A x, A y)} \varphi(t) d t\right) \leq \psi_{1}\left(\int_{0}^{d(B x, B y)} \varphi(t) d t\right)-\psi_{2}\left(\int_{0}^{d(B x, B y)} \varphi(t) d t\right)$,

where $\psi_{1} \in \Psi_{1}, \psi_{2} \in \Psi_{2}, \varphi \in \Psi_{3}$. Then there exist a unique common fixed point of $\mathrm{A}$ and $\mathrm{B}$ in $\mathrm{E}$.

In 2013, Gupta and Mani [16] proved another generalization of the result of Branciari [3] using real valued function.

Theorem 7 [16] Let $\mathrm{A}$ be a self map on complete metric space (E, d) such that for each $\mathrm{x}, \mathrm{y} \in \mathrm{E}$

$$
\int_{0}^{d(A x, A y)} \varphi(t) d t \leq \gamma(d(x, y)) \int_{0}^{m(x, y)} \varphi(t) d t
$$

and

$$
m(x, y)=\max \left\{\frac{d(x, A x) d(y, A y)}{d(x, y)}, d(x, y)\right\}
$$

where $\varphi \in \Psi_{3}$ and $\gamma: \mathrm{R}^{+} \rightarrow[0,1)$ is a function with

$$
\lim _{\delta \rightarrow t} \sup \gamma(\delta)<1, \quad \forall \quad t>0 .
$$

Then A has a unique fixed point in $\mathrm{E}$.

Some other results in complete metric spaces satisfying integral type contractions are mentioned in $[8,9,11,12,13,17,18]$

In 2014-15, Ansari [1] introduced the notion of C -class function as a major generalization of Banach contraction principle. Currently this finding is one of the most attractive research topics in fixed point theory. Some other special cases of C-class functions can be found in [2]. Ansari [1] gave the following definitions and examples.

Definition 1 [1] A mapping $\mathrm{F}:[0, \infty)^{2} \rightarrow \mathbb{R}$ is called $\mathrm{C}$-class function if it is continuous and satisfies following axioms:

1. $\mathrm{F}(\mathrm{r}, \mathrm{t}) \leq \mathrm{r}$ for all $\mathrm{r}, \mathrm{t} \in[0, \infty)$; 
2. $\mathrm{F}(\mathrm{r}, \mathrm{t})=\mathrm{r}$ implies that either $\mathrm{r}=0$ or $\mathrm{t}=0$;

Let us denote $\mathcal{C}$ the family of $\mathrm{C}$-class functions.

Remark 1 Clearly, for some $\mathrm{F}$ we have $\mathrm{F}(0,0)=0$.

Example 1 [1] The following functions $\mathrm{F}:[0, \infty)^{2} \rightarrow \mathbb{R}$ are elements of $\mathcal{C}$, for all $\mathrm{r}, \mathrm{t} \in[0, \infty)$ :

1. $F(r, t)=r-t, F(r, t)=r \Rightarrow t=0$;

2. $F(r, t)=m r, 0<m<1, F(r, t)=r \Rightarrow r=0$;

3. $\mathrm{F}(\mathrm{r}, \mathrm{t})=\frac{\mathrm{r}}{(1+\mathrm{t})^{\mathrm{h}}} ; \mathrm{h} \in(0, \infty), \mathrm{F}(\mathrm{r}, \mathrm{t})=\mathrm{r} \Rightarrow \mathrm{r}=0$ or $\mathrm{t}=0$;

4. $F(r, t)=\log \left(t+a^{r}\right) /(1+t), a>1, F(r, t)=r \Rightarrow r=0$ or $t=0$;

5. $F(r, t)=\ln \left(1+a^{r}\right) / 2, a>e, F(r, t)=r \Rightarrow r=0$;

6. $F(r, t)=(r+l)^{\left(1 /(1+t)^{p}\right)}-l, l>1, p \in(0, \infty), F(r, t)=r \Rightarrow t=0$;

7. $F(r, t)=r \log _{t+a} a, a>1, F(r, t)=r \Rightarrow r=0$ or $t=0$;

8. $F(r, t)=r-\left(\frac{1+r}{2+r}\right)\left(\frac{t}{1+t}\right), F(r, t)=r \Rightarrow t=0$;

9. $F(r, t)=r \beta(r), \beta:[0, \infty) \rightarrow[0,1), F(r, t)=r \Rightarrow r=0$;

10. $F(r, t)=r-\frac{t}{k+t}, F(r, t)=r \Rightarrow t=0$;

11. $\mathrm{F}(\mathrm{r}, \mathrm{t})=\mathrm{r}-\varphi(\mathrm{r}), \mathrm{F}(\mathrm{r}, \mathrm{t})=\mathrm{r} \Rightarrow \mathrm{r}=0$, here $\varphi:[0, \infty) \rightarrow[0, \infty)$ is a continuous function such that $\varphi(\mathrm{t})=0 \Leftrightarrow \mathrm{t}=0$;

12. $\mathrm{F}(\mathrm{r}, \mathrm{t})=\mathrm{rh}(\mathrm{r}, \mathrm{t}), \mathrm{F}(\mathrm{r}, \mathrm{t})=\mathrm{r} \Rightarrow \mathrm{r}=0$, here $\mathrm{h}:[0, \infty) \times[0, \infty) \rightarrow[0, \infty)$ is a continuous function such that $\mathrm{h}(\mathrm{r}, \mathrm{t})<1$ for all $\mathrm{t}, \mathrm{s}>0$;

13. $F(r, t)=r-\left(\frac{2+t}{1+t}\right) t, F(r, t)=r \Rightarrow t=0$.

14. $F(r, t)=\sqrt[n]{\ln \left(1+r^{n}\right)}, F(r, t)=r \Rightarrow r=0$

15. $\mathrm{F}(\mathrm{r}, \mathrm{t})=\phi(\mathrm{r}), \mathrm{F}(\mathrm{r}, \mathrm{t})=\mathrm{r} \Rightarrow \mathrm{r}=0$, here $\phi:[0, \infty) \rightarrow[0, \infty)$ is a upper semi-continuous function such that $\phi(0)=0$, and $\phi(\mathrm{t})<\mathrm{t}$ for $\mathrm{t}>0$, 
16. $\mathrm{F}(\mathrm{r}, \mathrm{t})=\frac{\mathrm{r}}{(1+\mathrm{r})^{\mathrm{s}}} ; \mathrm{s} \in(0, \infty), \mathrm{F}(\mathrm{r}, \mathrm{t})=\mathrm{r}$ implies $\mathrm{r}=0$.

Remark 2 We assume that is $\mathrm{F}$ increasing with respect to the first variable and decreasing with respect to the second variable.

The aim of this contribution is to investigate some fixed point results using the concept of $\mathrm{C}$-class function and control functions in the set up of complete metric spaces satisfying a generalized weak contraction. Our result mainly generalized the result of Rhoades [5] and Gupta and Mani [15].

\section{Main result- fixed point results with auxiliary functions}

The main result of this paper is the following theorem.

Theorem 8 Let $(\mathrm{E}, \mathrm{d})$ be a complete metric space and $\mathrm{A}: \mathrm{E} \rightarrow \mathrm{E}$ be a mapping such that for each $\mathrm{x}, \mathrm{y} \in \mathrm{E}$,

$$
\psi_{1}\left(\int_{0}^{\mathrm{d}(A x, A y)} \varphi(\mathrm{t}) \mathrm{dt}\right) \leq \mathrm{F}\left(\psi_{1}\left(\int_{0}^{\mathrm{M}(x, y)} \varphi(\mathrm{t}) \mathrm{dt}\right), \psi_{2}\left(\int_{0}^{M(x, y)} \varphi(t) d t\right)\right),
$$

where $\mathrm{F}$ is a $\mathrm{C}$-class function, $\psi_{1} \in \Psi_{1}, \psi_{2} \in \Psi_{2}, \varphi \in \Psi_{3}$ and

$$
M(x, y)=\max \left\{d(x, y), d(x, A x), d(y, A y), \frac{d(x, A y)+d(y, A x)}{2}\right\} .
$$

Then A has a unique fixed point.

Proof. Let $x_{0} \in E$ be an arbitrary point. Choose a point $x_{1}$ in $E$ such that $x_{1}=A x_{0}$. In general, choose $x_{n+1}$ such that $x_{n+1}=A x_{n}$ for $n=0,1,2 \cdots$. Suppose that $x_{n} \neq x_{n+1}$ for each integer $n>1$, then from (5)

$$
\psi_{1}\left(\int_{0}^{d\left(x_{n}, x_{n+1}\right)} \varphi(t) d t\right) \leq F\left\{\begin{array}{c}
\psi_{1}\left(\int_{0}^{M\left(x_{n-1}, x_{n}\right)} \varphi(t) d t\right) \\
\psi_{2}\left(\int_{0}^{M\left(x_{n-1}, x_{n}\right)} \varphi(t) d t\right)
\end{array}\right\},
$$

where from (6),

$$
M\left(x_{n-1}, x_{n}\right)=\max \left\{\begin{array}{c}
d\left(x_{n-1}, x_{n}\right), d\left(x_{n-1}, x_{n}\right), d\left(x_{n}, x_{n+1}\right), \\
\frac{d\left(x_{n-1}, x_{n+1}\right)+d\left(x_{n}, x_{n}\right)}{2}
\end{array}\right\}
$$




$$
\begin{aligned}
& =\max \left\{d\left(x_{n-1}, x_{n}\right), d\left(x_{n}, x_{n+1}\right), \frac{d\left(x_{n-1}, x_{n+1}\right)}{2}\right\} \\
& =\max \left\{d\left(x_{n-1}, x_{n}\right), d\left(x_{n}, x_{n+1}\right)\right\} .
\end{aligned}
$$

If $d\left(x_{n}, x_{n+1}\right) \geq d\left(x_{n-1}, x_{n}\right)$ for some $n$, then on combining equation (7) and (8), we get

$$
\psi_{1}\left(\int_{0}^{d\left(x_{n}, x_{n+1}\right)} \varphi(t) d t\right) \leq F\left\{\begin{array}{l}
\psi_{1}\left(\int_{0}^{d\left(x_{n}, x_{n+1}\right)} \varphi(t) d t\right) \\
\psi_{2}\left(\int_{0}^{d\left(x_{n}, x_{n+1}\right)} \varphi(t) d t\right)
\end{array}\right\} .
$$

Thus by definition of $F \in \mathcal{C}$, we get

$$
\text { either } \psi_{1}\left(\int_{0}^{\mathrm{d}\left(x_{\mathfrak{n}}, x_{\mathfrak{n}+1}\right)} \varphi(t) d t\right)=0 \text { or } \psi_{2}\left(\int_{0}^{\mathrm{d}\left(x_{\mathfrak{n}}, x_{\mathfrak{n}+1}\right)} \varphi(t) d t\right)=0
$$

From definition of $\psi_{1}$ and $\psi_{2}$, it is possible only if

$$
\int_{0}^{d\left(x_{n}, x_{n+1}\right)} \varphi(t) d t=0 .
$$

This is a contradiction to our hypothesis. Thus $d\left(x_{n}, x_{n+1}\right)<d\left(x_{n-1}, x_{n}\right)$, this implies

$$
\begin{aligned}
\psi_{1}\left(\int_{0}^{\mathrm{d}\left(x_{n}, x_{n+1}\right)} \varphi(t) d t\right) & \leq F\left(\psi_{1} \int_{0}^{\mathrm{d}\left(x_{n-1}, x_{n}\right)} \varphi(t) d t, \psi_{1} \int_{0}^{d\left(x_{n-1}, x_{n}\right)} \varphi(t) d t\right) \\
& \leq \psi_{1} \int_{0}^{d\left(x_{n-1}, x_{n}\right)} \varphi(t) d t
\end{aligned}
$$

Since $\psi_{1}$ is continuous and non-decreasing, therefore

$$
\int_{0}^{d\left(x_{n}, x_{n+1}\right)} \varphi(t) d t \leq \int_{0}^{d\left(x_{n-1}, x_{n}\right)} \varphi(t) d t
$$

thus $\left\{\int_{0}^{\left(d\left(x_{n}, x_{n+1}\right)\right.} \varphi(t) d t\right\}$ is monotone decreasing and lower bounded sequence. Therefore there exist $r \geq 0$ such that

$$
\lim _{n \rightarrow \infty} \int_{0}^{d\left(x_{n}, x_{n+1}\right)} \varphi(t) d t=r .
$$


Suppose that $r>0$. Taking limit as $n \rightarrow \infty$ on both sides of eq. (9) and using eq. (10), we get

$$
\psi_{1}(r) \leq F\left(\psi_{1}(r), \psi_{2}(r)\right),
$$

implies from definition of $F \in \mathcal{C}$ that

$$
\text { either } \psi_{1}(r)=0 \text { or } \psi_{2}(r)=0 \text {. }
$$

Consequently, by definition of $\psi_{1}$ and $\psi_{2}$, we get $r=0$.

Hence from eq. (10), we obtain

$$
\lim _{n \rightarrow \infty} \int_{0}^{d\left(x_{n}, x_{n+1}\right)} \varphi(t) d t=0,
$$

implies

$$
\lim _{n \rightarrow \infty} d\left(x_{n}, x_{n+1}\right)=0 .
$$

Next we prove that $\left\{x_{n}\right\}$ is a Cauchy sequence. Suppose it is not. Therefore for an $\epsilon>0$, there exists two sub-sequences $\left\{x_{\mathfrak{m}(p)}\right\}$ and $\left\{x_{\mathfrak{n}(p)}\right\}$ of $\left\{x_{n}\right\}$ with $\mathrm{m}(\mathrm{p})<\mathrm{n}(\mathrm{p})<\mathrm{m}(\mathrm{p}+1)$ such that

$$
\mathrm{d}\left(\mathrm{x}_{\mathrm{m}(\mathrm{p})}, x_{\mathfrak{n}(\mathfrak{p})}\right) \geq \epsilon, \quad \mathrm{d}\left(\mathrm{x}_{\mathrm{m}(\mathrm{p})}, x_{\mathfrak{n}(\mathrm{p})-1}\right)<\epsilon .
$$

Consider

$$
\begin{aligned}
& \psi_{1}\left(\int_{0}^{\epsilon} \varphi(t) d t\right) \leq \psi_{1}\left(\int_{0}^{d\left(x_{\mathfrak{m}(p)}, x_{\mathfrak{n}(p)}\right)} \varphi(t) d t\right) \\
& \leq F\left\{\begin{array}{c}
\psi_{1}\left(\int_{0}^{M\left(x_{\mathfrak{m}(p)-1}, x_{\mathfrak{n}(\mathfrak{p})-1}\right)} \varphi(t) d t\right), \\
\psi_{2}\left(\int_{0}^{M\left(x_{\mathfrak{m}(\mathfrak{p})-1}, x_{\mathfrak{n}(\mathfrak{p})-1}\right)} \varphi(t) d t\right)
\end{array}\right\} .
\end{aligned}
$$

Using (6)

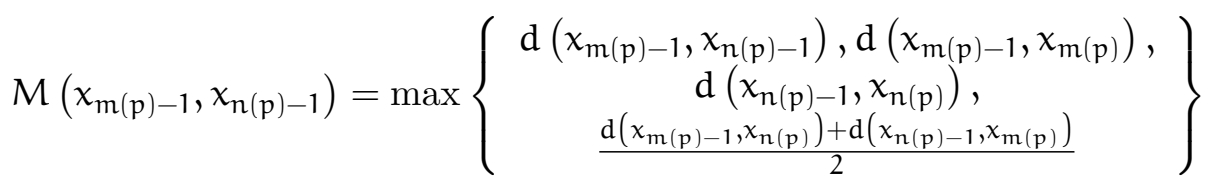

$$
\begin{aligned}
& =\max \left\{\begin{array}{c}
\mathrm{d}\left(x_{\mathfrak{m}(\mathfrak{p})-1}, x_{\mathfrak{n}(\mathrm{p})-1}\right), \mathrm{d}\left(x_{\mathfrak{m}(\mathrm{p})-1}, x_{\mathfrak{m}(\mathfrak{p})}\right), \\
d\left(x_{\mathfrak{n}(\mathrm{p})-1}, x_{\mathfrak{n}(\mathfrak{p})}\right), z(m, n)
\end{array}\right\},
\end{aligned}
$$


where,

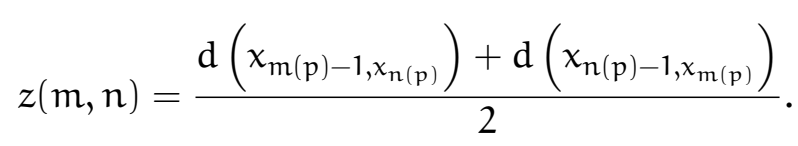

Thus

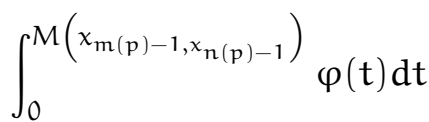

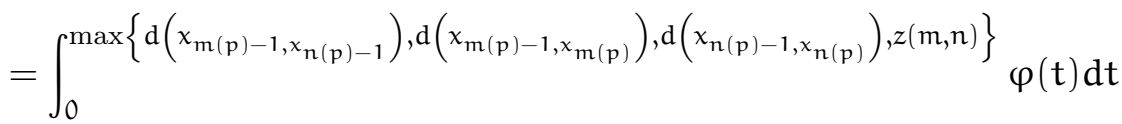

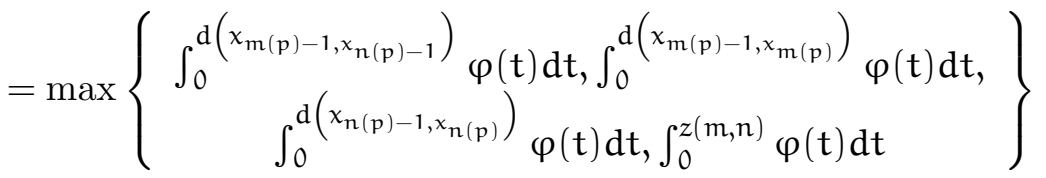

Using (13) and triangle inequality, we get

$$
\begin{aligned}
\mathrm{d}\left(x_{\mathfrak{m}(\mathfrak{p})-1}, x_{\mathfrak{n}(\mathfrak{p})-1}\right) & \leq \mathrm{d}\left(x_{\mathfrak{m}(\mathfrak{p})-1}, x_{\mathfrak{m}(\mathfrak{p})}\right)+\mathrm{d}\left(x_{\mathfrak{m}(\mathfrak{p})}, x_{\mathfrak{n}(\mathfrak{p})-1}\right) \\
& <\mathrm{d}\left(x_{\mathfrak{m}(\mathfrak{p})-1}, x_{\mathfrak{m}(\mathfrak{p})}\right)+\epsilon .
\end{aligned}
$$

Therefore,

$$
\lim _{p \rightarrow \infty} \int_{0}^{d\left(x_{\mathfrak{m}(p)-1}, x_{\mathfrak{n}(p)-1}\right)} \varphi(t) d t \leq \int_{0}^{\epsilon} \varphi(t) d t .
$$

Also,

$$
\begin{aligned}
& z(m, n)=\frac{d\left(x_{\mathfrak{m}(\mathfrak{p})-1}, x_{\mathfrak{n}(\mathfrak{p})}\right)+d\left(x_{\mathfrak{n}(\mathfrak{p})-1}, x_{\mathfrak{m}(\mathfrak{p})}\right)}{2} \\
& \leq \frac{d\left(x_{m(p)-1}, x_{m(p)}\right)+2 d\left(x_{m(p)}, x_{n(p)-1}\right)+d\left(x_{n(p)-1}, x_{n(p)}\right)}{2} \\
& \leq \frac{\mathrm{d}\left(x_{\mathfrak{m}(\mathrm{p})-1}, x_{\mathfrak{m}(\mathrm{p})}\right)+\mathrm{d}\left(x_{\mathfrak{n}(\mathrm{p})-1}, x_{\mathfrak{n}(\mathrm{p})}\right)}{2}+\epsilon .
\end{aligned}
$$

Taking limit as $p \rightarrow \infty$ and using (12), we get

$$
\lim _{p \rightarrow \infty} \int_{0}^{z(m, n)} \varphi(t) d t \leq \int_{0}^{\epsilon} \varphi(t) d t
$$


Taking limit as $p \rightarrow \infty$ in equality (14) and using equations (15), (16), (17), (18) and (19) all together in (14), we get

$$
\psi_{1}\left(\int_{0}^{\epsilon} \varphi(t) d t\right) \leq F\left(\psi_{1}\left(\int_{0}^{\epsilon} \varphi(t) d t\right), \psi_{2}\left(\int_{0}^{\epsilon} \varphi(t) d t\right)\right) .
$$

Again from definition of $F \in \mathcal{C}$ we get,

$$
\text { either } \psi_{1}\left(\int_{0}^{\epsilon} \varphi(t) d t\right)=0 \text { or } \psi_{2}\left(\int_{0}^{\epsilon} \varphi(t) d t\right)=0 .
$$

It is possible only if, $\int_{0}^{\epsilon} \varphi(t) d t=0$. This is a contradiction to our hypothesis. Therefore $\left\{x_{n}\right\}$ is a Cauchy sequence, call the limit $\alpha$ such that

$$
\lim _{n \rightarrow \infty} A x_{n-1}=\alpha .
$$

Next we claim that $\alpha$ is the fixed point of map $A$.

That is $A \alpha=\alpha$, suppose it is not. Then $d(A \alpha, \alpha)>0$.

Let $\delta=d(A \alpha, \alpha)$.

Consider,

$$
\begin{aligned}
\psi_{1}\left(\int_{0}^{\delta} \varphi(t) d t\right) & =\psi_{1}\left(\int_{0}^{\mathrm{d}(\mathrm{A} \alpha, \alpha)} \varphi(\mathrm{t}) \mathrm{dt}\right) \\
& \leq \mathrm{F}\left\{\begin{array}{c}
\psi_{1}\left(\int_{0}^{\mathrm{M}\left(\alpha, x_{\mathrm{n}}\right)} \varphi(\mathrm{t}) \mathrm{dt}\right), \\
\psi_{2}\left(\int_{0}^{\mathrm{M}\left(\alpha, x_{\mathrm{n}}\right)} \varphi(\mathrm{t}) \mathrm{dt}\right)
\end{array}\right\},
\end{aligned}
$$

where,

$$
M\left(\alpha, x_{n}\right)=\max \left\{\begin{array}{c}
d\left(\alpha, x_{n}\right), d(\alpha, A \alpha), d\left(x_{n}, x_{n+1}\right), \\
\frac{d\left(\alpha, x_{n+1}\right)+d\left(x_{n}, A \alpha\right)}{2}
\end{array}\right\} .
$$

Since,

$$
\lim _{n \rightarrow \infty} d\left(\alpha, x_{n}\right)=\lim _{n \rightarrow \infty} d\left(x_{n}, x_{n+1}\right)=\lim _{n \rightarrow \infty} d\left(\alpha, x_{n+1}\right)=0 .
$$

Taking $\lim _{n \rightarrow \infty}$ in (21) and by using (20), (22), (23), we get

$$
\psi_{1}\left(\int_{0}^{\delta} \varphi(t) d t\right) \leq \mathrm{F}\left\{\begin{array}{c}
\psi_{1}\left(\int_{0}^{\max \left\{\mathrm{d}(\alpha, \mathrm{A} \alpha), \frac{\mathrm{d}(\alpha, \mathrm{A} \alpha)}{2}\right\}} \varphi(\mathrm{t}) \mathrm{dt}\right), \\
\psi_{2}\left(\int_{0}^{\max \left\{\mathrm{d}(\alpha, \mathrm{A} \alpha), \frac{\mathrm{d}(\alpha, \mathrm{A} \alpha)}{2}\right\}} \varphi(\mathrm{t}) \mathrm{dt}\right)
\end{array}\right\}
$$




$$
\leq F\left\{\psi_{1}\left(\int_{0}^{\delta} \varphi(t) d t\right), \psi_{2}\left(\int_{0}^{\delta} \varphi(t) d t\right)\right\}
$$

Thus we obtain,

$$
\text { either } \psi_{1}\left(\int_{0}^{\delta} \varphi(t) d t\right)=0 \text { or } \psi_{2}\left(\int_{0}^{\delta} \varphi(t) d t\right)=0
$$

that is $\int_{0}^{\delta} \varphi(t) d t=0$. Hence $\delta=0$.

This implies $d(A \alpha, \alpha)=0$. Therefore $\alpha$ is the fixed point of map $A$. Uniqueness of the fixed point can be easily obtain by using above inequality (21), (22), (24). This proves the main result.

\section{Applications and example}

Next we give several corollaries, as a application of our main result, in the underlying spaces. Some of them are novel in literature

If we take $\psi_{1}(t)=t$ in Theorem 8 , we get a new result.

Corollary 1 Let $(\mathrm{E}, \mathrm{d})$ be a complete metric space and $\mathrm{A}: \mathrm{E} \rightarrow \mathrm{E}$ be a mapping such that for each $\mathrm{x}, \mathrm{y} \in \mathrm{E}$,

$$
\int_{0}^{\mathrm{d}(A x, A y)} \varphi(\mathrm{t}) \mathrm{dt} \leq \mathrm{F}\left(\int_{0}^{M(x, y)} \varphi(\mathrm{t}) \mathrm{dt}, \psi_{2}\left(\int_{0}^{M(x, y)} \varphi(\mathrm{t}) \mathrm{dt}\right)\right)
$$

for each $\mathrm{x}, \mathrm{y} \in \mathrm{E}$, where $\mathrm{M}(\mathrm{x}, \mathrm{y})$ is given in (6), $\mathrm{F}$ is a C-class function, $\psi_{2} \in \Psi_{2}, \varphi \in \Psi_{3}$.

Then A has a unique fixed point.

If we take $F(r, t)=\frac{r}{(1+t)^{s}}$ and assume $s=1$ in Theorem 8, we find a very interesting novel result.

Corollary 2 Let $(\mathrm{E}, \mathrm{d})$ be a complete metric space and $\mathrm{A}: \mathrm{E} \rightarrow \mathrm{E}$ be a mapping such that for each $\mathrm{x}, \mathrm{y} \in \mathrm{E}$,

$$
\psi_{1}\left(\int_{0}^{\mathrm{d}(A x, A y)} \varphi(\mathrm{t}) \mathrm{dt}\right) \leq \frac{\psi_{1}\left(\int_{0}^{M(x, y)} \varphi(t) d t\right)}{1+\psi_{2}\left(\int_{0}^{M(x, y)} \varphi(t) d t\right)},
$$

where $M(x, y)$ is given in (6), $\psi_{1} \in \Psi_{1}, \psi_{2} \in \Psi_{2}, \varphi \in \Psi_{3}$.

Then A has a unique fixed point. 
If we take $F(r, t)=\lambda r$ for $0<\lambda<1$ and in Theorem 8 , then we have following corollary.

Corollary 3 Let $(\mathrm{E}, \mathrm{d})$ be a complete metric space and $\mathrm{A}: \mathrm{E} \rightarrow \mathrm{E}$ be a mapping such that for each $\mathrm{x}, \mathrm{y} \in \mathrm{E}$,

$$
\psi_{1}\left(\int_{0}^{\mathrm{d}(A x, A y)} \varphi(t) d t\right) \leq \lambda \psi_{1}\left(\int_{0}^{M(x, y)} \varphi(t) d t\right),
$$

where $M(x, y)$ is given in (6), $\psi_{1} \in \Psi_{1}, \varphi \in \Psi_{3}$.

Then A has a unique fixed point.

If we assume that $\psi_{1}(t)=t$ in Corollary 3 then we obtain the result of Rhoades [5] (see Theorem 2 of [5]).

Corollary 4 Let $(\mathrm{E}, \mathrm{d})$ be a complete metric space and $\mathrm{A}: \mathrm{E} \rightarrow \mathrm{E}$ be a mapping such that for each $\mathrm{x}, \mathrm{y} \in \mathrm{E}$,

$$
\int_{0}^{\mathrm{d}(A x, A y)} \varphi(\mathrm{t}) \mathrm{dt} \leq \lambda \int_{0}^{\mathrm{M}(x, y)} \varphi(\mathrm{t}) \mathrm{dt}
$$

where $\mathrm{M}(\mathrm{x}, \mathrm{y})$ is given in (6), $\varphi \in \Psi_{3}$.

Then A has a unique fixed point.

If we take $F(r, t)=r-t$ in Theorem 8, then we obtain the result of Gupta and Mani [15].

Corollary 5 Let $(\mathrm{E}, \mathrm{d})$ be a complete metric space and $\mathrm{A}: \mathrm{E} \rightarrow \mathrm{E}$ be a mapping such that for each $\mathrm{x}, \mathrm{y} \in \mathrm{E}$,

$$
\psi_{1}\left(\int_{0}^{\mathrm{d}(A x, A y)} \varphi(t) d t\right) \leq \psi_{1}\left(\int_{0}^{M(x, y)} \varphi(t) d t\right)-\psi_{2}\left(\int_{0}^{M(x, y)} \varphi(t) d t\right)
$$

where $M(x, y)$ is given in (6), $\psi_{1} \in \Psi_{1}, \psi_{2} \in \Psi_{2}, \varphi \in \Psi_{3}$.

Then A has a unique fixed point.

Remark 3 It should be noted that in [15], authors have considered an extra condition on $\psi_{2}$. But from above corollaries it is clear that we can deduce the same result without that extra assumption. Also, the result obtained in [5] and [15] are an element of $\mathcal{C}$ - class function as shown in Corollary 4 and Corollary 5. So the main result of this paper is more generalized than the other previously proved results. 
Now, we gave a non trivial example to justify the importance of our result.

Example 2 Let $\mathrm{E}=\mathrm{N}-\{\infty\}$ and $\mathrm{d}$ is usual metric on $\mathrm{E}$. Define a self maps A on $\mathrm{E}$ such that

$$
\mathrm{A} x=\frac{x}{3}, \quad \forall \quad x \in \mathrm{E} .
$$

Define a function $\mathrm{F}:[0, \infty)^{2} \rightarrow \mathbb{R}$ as

$$
\mathrm{F}(\mathrm{r}, \mathrm{t})=\mathrm{mr}, \quad \forall 0<\mathrm{m}=\frac{2}{3}<1 .
$$

Then clearly, $\mathrm{F}$ is a $\mathrm{C}$-class function.

Let us define $\psi_{1}, \varphi:[0,+\infty) \rightarrow[0,+\infty)$ as

$$
\psi_{1}(\mathrm{t})=\mathrm{t}, \quad \varphi(\mathrm{t})=\frac{\mathrm{t}}{2}, \quad \forall \quad \mathrm{t} \in[0,+\infty)
$$

then for each $€>0$, clearly

$$
\int_{0}^{\epsilon} \varphi(t) d t=\frac{\epsilon^{2}}{4}>0 .
$$

If $\mathrm{x}=\mathrm{y}$ for all $\mathrm{x}, \mathrm{y} \in \mathrm{E}$, then result holds trivially.

So suppose that $\mathrm{x} \neq \mathrm{y}$ for all $\mathrm{x}, \mathrm{y} \in \mathrm{E}$.

Since $\mathrm{d}$ is usual metric for all $\mathrm{x}, \mathrm{y} \in \mathrm{E}$, then on careful calculation, we get

$$
\text { L.H.S. }=\frac{|x-y|^{2}}{36} \text {, }
$$

and

$$
\text { R.H.S. }=\frac{|x-y|^{2}}{3},
$$

Then clearly, L.H.S $\leq$ R.H.S for all $\mathrm{x}, \mathrm{y} \in \mathrm{E}$ and, hence all conditions of Theorem 8 are verified.

Clearly $0 \in \mathrm{E}$ is the unique fixed point of $\mathrm{A}$.

\section{References}

[1] A. H. Ansari, Note on $\phi-\psi$ contractive type mappings and related fixed point, in: Proceedings of the 2nd Regional Conference on Mathematics And Applications, PNU, Iran, 2014, pp. 377-380. 
[2] A. H. Ansari, S. Chandok and C. Ionescu, Fixed point theorems on bmetric spaces for weak contractions with auxiliary functions, J. Inequal. Appl., 2014 (2014), 1-17.

[3] A. Branciari, A fixed point theorem for mappings satisfying a general contractive condition of integral type, Int. J. Math. Math. Sci., 29 (2002), $531-536$.

[4] B. K. Dass and S. Gupta, An extension of Banach contraction principle through rational expression, Indian J. Pure Appl. Math., 12 (1975), 14551458 .

[5] B. E. Rhoades, Two fixed point theorems for mapping satisfying a general contractive condition of integral type, Int. J. Math. Math. Sci., 2003 (2003), 4007-4013.

[6] B. Samet and H. Yazidi, Fixed point theorems with respect to a contractive condition of integral type, Rend. Cric. Mat. Palermo., 60 (2011), 181-190.

[7] G. V. R. Babu and G. N. Alemayehu, Point of coincidence and common fixed points of a pair of generalized weakly contractive maps, Journal of Advanced Research in Pure Mathematics, 2 (2010), 89-106.

[8] N. Mani, Generalized $C_{\beta}^{\psi}$-rational contraction and fixed point theorem with application to second order differential equation, Mathematica Moravica, 22 (1) (2018), 43-54.

[9] N. Sharma, N. Mani, N. Gulati, Unique fixed point results for pairs of mappings on complete metric spaces, Ital. J. Pure Appl. Math., 42 (2) (2019), 798-808

[10] S. Banach, Sur les operations dans les ensembles abstraits et leur application aux equations integrals, Fundam. Math., 3 (1922), 133-181.

[11] S. M. A. Aleomraninejad and M. Shokouhnia, Some fixed point results of integral type and applications, Fixed Point Theory, 5 (2015), 101-109.

[12] S. Radenovic, A note on fixed point theory for cyclic phi -contractions, Fixed Point Theory Appl., 2015 (2015), 1-9.

[13] U. C. Gairola and A. S. Rawat, A fixed point theorem for two pair of maps satisfying a new contractive condition of integral type, Int. Math. Forum, 4 (2009), 177-183. 
[14] V. Gupta and N. Mani, A common fixed point theorem for two weakly compatible mappings satisfying a new contractive condition of integral type, Mathematical Theory and Modeling, 1 (2011), 1- 6.

[15] V. Gupta, N. Mani and A. K. Tripathi, A fixed point theorem satisfying a generalized weak contractive condition of integral type, Int. J. Math. Anal., Ruse, 6 (2012), 1883-1889.

[16] V. Gupta and N. Mani, Existence and uniqueness of fixed point for contractive mapping of integral type, Int. J. Comput. Sci. Math., 4 (2013), $72-83$.

[17] V. Gupta, N. Mani, N. Sharma, Fixed point theorems for weak $(\psi, \beta)$ mappings satisfying generalized C-condition and its application to boundary value problem, Computational and Mathematical Methods, 1 (2019), e1041.

[18] Z. Q. Liu, X. Zou and S. M. Kang, Fixed point theorems of contractive mappings of integral type, Fixed Point Theory and Appl., 2013.

Received: November 17, 2019 